excellent impression of the industries. The author is to be congratulated, and Dr. Hallam L. Movius, jun., who edited it, and the American Philosophical Society are to be thanked for the production of a very important publication which fills a gap in our knowledge of early Palæolithic cultures in the Leipzig region.

\section{A Barking Crayfish}

AN unusual example of a 'barking' crayfish has been. reported from Newcastle, Australia (Austral. Mus. Mag., 12, No. 2). Only one other example of the species (Linuparus trigonus) had previously been recognized around the Australian coastline; that specimen was also collected in seas adjoining the temperate eastern quarter of the continent and as recently as 1949. Both occurrences are surprise distributions of a crayfish which belongs to the Japanese seas. The strange noise made by the species has probably passed unnoticed until it was heard by Athol D'Ombrain as a harsh, grating noise. Its source was not located until some time after the death of the Newcastle specimen. Finally it was traced to the inner angles of the heavy basal joints of the stubby antennæ, immediately in front of the eyes. Here there are two smooth-lined cavities which enclose and bear upon a pair of highly polished bosses when the antennæ assemblage is thrown back. wards over the head. Even after death a semblance of this friction-produced sound could readily be achieved by hand manipulation. The purpose of the 'barking' is not clear.

\section{Zoo!ogical Nomenclature}

THE International Commission on Zoological Nomenclature gives notice that as from December 26,1956 , it will start voting on the following cases involving the possible use of its plenary powers for the purposes specified against each entry. Full details are given in the Bulletin of Zoological Nomenclature (12, Pt. 3): (1) Lepidurus Leach, 1819, validation; Triops Schrank, 1803, determination of gender and designation of type species for (Cl. Crustacea, Order Decapoda); (2) Apodinae Hartert, 1897, (Cl. Aves), validation; (3) volvulus (emend. of volvulas) (Filaria), validation of, as from Leuckart, [1892] (Cl. Nematoda); (4) Asaphus Brongniart, 1822, validation of and designation of type species for ; cornigerus Schlothөim, 1820 (Trilobites), suppression (Cl. Trilobita). Comments should be sent as soon as possible to Francis Hemming, Secretary to the Commission, 28 Park Village East, Regent's Park, London, N.W.1.

\section{Cytogenetics and Breeding of Sugar-Cane}

THE improvement of sugar-cane (Saccharum officinarum) by breeding and selection is of comparatively recent origin. Much work, however, is now going on in different tropical regions. T. S. Raghavan (Proc. Indian Acad. Sci., 43, B, 2, 100 ; 1956) has pointed out that although the main aim in breeding work is to obtain high-yielding commercial cane, breeding for resistance to diseases is of great importance in some regions. Hybridization of different species of Saccharum, and sometimes of different related genera, has been necessary to obtain strains well suited to the needs of different regions. Where cane develops under favourable conditions, the noble (S. officinarum) and highly nobilized varieties have given good results as parents, while in less favourable areas $S$. spon- taneum and $S$. barberi have given more satisfaction. At Coimbatore, S. spontaneum, and in Florida $S$. robustum, have proved of value in breeding programmes. Important intergeneric crosses are those with bamboo and Sorghum. Sugar-cane as a breeding material is fundamentally different from other commercial crops. It is a highly heterozygous polyploid complex with a large reserve of lethal genes which, especially in $S$. officinarum, are responsible for there being practically no survivals in the selfed progeny. It is only clonal propagation that has made it survive. Arising mainly out of its genetical impurity and high allopolyploidy, no prediction can be made as to the nature of the progeny to be expected in a cross. The high heterozygosity of the chromosomal material of both the parents renders odds against anticipating any desired combination. The occurrence of parthenogenesis and of chromosome elimination has raised new issues which are now recognized in the cytogenetic approach to practical problems. Lists of crosses and of parental and hybrid chromosome numbers are given.

\section{Use of Silage in British Agriculture}

Fermented green fodder has now come to be recognized as a valuable supplement to the traditional roots and hay for winter feeding of cattle. It also fits in admirably with the present-day intensification in Britain of grassland management based on increased use of fertilizer. It is therefore important that the facts concerning silage making and use should be brought thoroughly up to date and presented in a clear practical manner together with just enough of the theory to make the rules comprehensible. This task has been admirably carried out

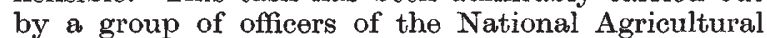
Advisory Service and published as a revision (the seventh) of Bulletin No. 37, "Silage", of the Ministry of Agriculture (pp. $58+4$ plates. London : H.M.S.O., 1956. 3s. net). Silage, properly made, has a feeding value about twice that of roots and rather more than that of hay, reckoned on a starch-equivalent basis. It is readily eaten by cattle, and fortunately many of the operations of growing, cutting, carting and making lend themselves to mechanization, an aspect of the subject which rightly occupies an important place in the treatment. Grass is not the only crop suitable for silage making, though it is the most important ; the use of arable crops, including by-products such as sugar-beet tops, is dealt with. The addition of extra carbohydrate as molasses to high-protein crops in order to secure a favourable fermentation is alse explained. On the national level, any farming practice which can reduce the expensive imports of concentrated feeding stuffs into Britain deserves official encouragement. To put the facts before farmers is clearly a step in the right direction.

\section{A Survey of Atomic Energy}

THe spring issue of Studies, the Irish quarterly review, contains an interesting article entitled "Atomic Structure and Atomic Energy", by Prof. T. S. Wheeler, professor of chemistry in University College, Dublin, in which he gives an excellent summary of our present knowledge of the structure of the atom and the production of atomic energy. The component parts of the atom, isotopes, the relationship between matter and energy, nuclear fission, the uranium and plutonium bombs, nuclear reactors, and the British programme of nuclear. 